\title{
Antimicrobial resistance of Pasteurella multocida type $B$ isolates associated with acute septicemia in pigs and cattle in Spain
}

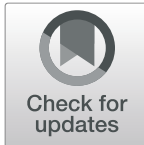

Inmaculada Cuevas ${ }^{1}$, Alfonso Carbonero ${ }^{1}$, David Cano ${ }^{1}$, Ignacio García-Bocanegra ${ }^{1}$, Manuel Ángel Amaro ${ }^{2}$ and Carmen Borge ${ }^{1 *}$ D

\begin{abstract}
Background: Pasteurella multocida is the etiological agent responsible for several diseases in a wide range of hosts around the world and thus, causes serious economic losses. Acute septicemia associated with capsular type B P. multocida has recently emerged in Europe and continuous outbreaks of these acute processes have been described in Spain since they were first detected in pigs in 2009 and cattle in 2015. The scarcity of studies on the antimicrobial susceptibility of this capsular type of $P$. multocida and growing concern about the general increase of antimicrobial resistance mean that studies related to the performance of type $B$. multocida against antibiotics are necessary to establish accurate treatments and to monitor antimicrobial resistances.
\end{abstract}

Results: Seventy-six isolates of $P$. multocida type B from pigs and cattle with acute septicemia were tested for susceptibility to 10 different antimicrobials. Bovine isolates were susceptible to all the antibiotics we tested except for lincomycin (94.4\% of isolates were resistant). However, the antimicrobials we tested were less effective against swine isolates, of which none were susceptible to lincomycin. Furthermore, $29.3 \%$ swine isolates were resistant to tetracycline, $27.6 \%$ to penicillin, $20.7 \%$ to oxytetracycline, $17.3 \%$ to chloramphenicol, $15.5 \%$ to gentamicin, and $3.4 \%$ to enrofloxacin; no resistance to ceftiofur was detected. No multidrug resistant isolates were detected from cattle, while $25.86 \%$ of swine isolates were resistant to three or more antibiotic classes.

Conclusions: In this study, the lower resistance rates and multidrug resistant isolates reported for $P$. multocida type $B$ derived from cattle compared to those isolated from pigs may be related to the increased use of antibiotics in the porcine industry in Spain. Lincomycin is not recommended for the treatment of acute septicemia in pigs or cattle, rather, the use of ceftiofur, enrofloxacin, or gentamicin is indicated as an emergency treatment in the early stages of disease; once the susceptibility results are known, the use of tetracyclines, penicillin, or chloramphenicol should be prioritized. The increase in multidrug resistant isolates and antimicrobial resistance rates indicates that more attention should be paid to prevention as well as the responsible use of antibiotics.

Keywords: Pasteurella multocida, Type B, Antimicrobial susceptibility, Resistance, Hemorrhagic septicemia

\footnotetext{
* Correspondence: sa2borom@uco.es

'Department of Animal Health (AGR-149). Campus of International Agri-Food Excellence CeiA3, University of Córdoba, Rabanales University Campus, 14071 Córdoba, Spain

Full list of author information is available at the end of the article
}

(C) The Author(s). 2020 Open Access This article is licensed under a Creative Commons Attribution 4.0 International License, which permits use, sharing, adaptation, distribution and reproduction in any medium or format, as long as you give appropriate credit to the original author(s) and the source, provide a link to the Creative Commons licence, and indicate if changes were made. The images or other third party material in this article are included in the article's Creative Commons licence, unless indicated otherwise in a credit line to the material. If material is not included in the article's Creative Commons licence and your intended use is not permitted by statutory regulation or exceeds the permitted use, you will need to obtain permission directly from the copyright holder. To view a copy of this licence, visit http://creativecommons.org/licenses/by/4.0/. The Creative Commons Public Domain Dedication waiver (http://creativecommons.org/publicdomain/zero/1.0/) applies to the data made available in this article, unless otherwise stated in a credit line to the data. 


\section{Background}

Even though Pasteurella multocida is commonly present in the upper respiratory tract of domestic and wild species and it is considered an opportunistic agent, this microorganism is, in fact, the primary etiological cause of a wide range of diseases with global economic importance [1]. P. multocida affects a broad range of hosts and causes many diseases including pneumonia in pigs, cattle, small ruminants, and rabbits, acute septicemia in cattle and buffalo, atrophic rhinitis in swine, and fowl cholera in poultry [2-5].

The acute septicemia caused by $P$. multocida is associated with hemorrhagic septicemia (HS), a severe disease which involves the capsular types $\mathrm{B}$ and $\mathrm{E}$ of this microorganism [4]. HS is endemic in some areas of Asia and Africa and commonly affects cattle and buffalo, but is also infrequently reported in pigs [6]. However, only sporadic outbreaks of HS affecting pigs have been described in limited geographic areas including India [7], Sri Lanka [8], Vietnam [6], and Australia [9].

Capsular type B P. multocida causing acute septicemia has recently emerged in Europe. The first outbreak of HS caused by this agent was reported in 2009 in Spain and affected Iberian pigs from seven herds reared in an extensive farm system [10]. Since then, several authors have described periodic outbreaks of acute septicemia in Iberian pigs [11], wild boar [12] and cattle [13] in Spain. Additionally, sporadic outbreaks of HS in pigs and cattle have also recently been reported in Hungary [14, 15].

Antimicrobial therapy is still proven to be effective in the treatment of diseases caused by $P$. multocida, including HS. The etiological treatment of this disease is based on the parenteral administration of antibiotics (e.g., penicillin, ampicillin, tetracycline, chloramphenicol, streptomycin, or neomycin), which are only effective in affected animals in the early stages of disease $[4,16]$. However, the excessive and unreasonable use of antimicrobials has accelerated the selective pressure put on the expression of genes encoding resistance in these microorganisms thus, increasing the emergence of resistant isolates [17]. Indeed, an increase in the incidence of multidrug resistant (MDR) pathogenic bacteria has been reported in recent decades [18] and is decreasing the efficacy of currently available antibiotics used to treat infectious diseases in foodproducing animals.

Moreover, antimicrobial resistances impact public health because of the potential for zoonotic bacteria to pass onto humans through the food chain [19]. The growing concern about the increase in antimicrobial resistances has meant that national and international action has been taken to monitor, harmonize, and prudently use antibiotics [20, 21]. The World Organisation for Animal Health (OIE) and World Health Organisation (WHO) have each developed a list of critically important antimicrobial agents in veterinary medicine and human medicine, respectively $[22,23]$.

The proper use of antibiotics to control pasteurellosis will require the completion of detailed surveys in several geographical areas [17]. Furthermore, because of the recent emergence and circulation of $P$. multocida type $\mathrm{B}$ in Europe and the lack of studies regarding the response of this capsular type to antibiotics, its antimicrobial susceptibility profile must be determined in order to establish accurate treatments and to detect and monitor antibiotic resistances.

\section{Results}

Seventy-six isolates from swine $(n=58)$ and cattle $(n=18)$ affected with acute septicemic pasteurellosis caused by $P$. multocida type B, biovar 3 were tested for susceptibility to 10 different antimicrobial agents. The percentage of isolates which were susceptible, intermediate, or resistant to each antibiotic are listed in Table 1 and their minimum inhibitory concentration (MIC) distribution and $\mathrm{MIC}_{50}$ and $\mathrm{MIC}_{90}$ are shown in Tables 2 and 3.

Most isolates were susceptible to the antimicrobial agents tested, except for lincomycin: 100\% of porcine isolates and $94.4 \%$ of bovine isolates were resistant to this drug. There was no evidence of any resistance to enrofloxacin, ceftiofur, gentamicin, chloramphenicol, oxytetracycline, or tetracycline in bovine isolates. Bacteria isolated from cattle only showed a high percentage of resistance to lincomycin, with low levels of resistance to penicillin (5.6\%). Regarding the porcine isolates, $29.3 \%$ were resistant to tetracycline, $27.6 \%$ to penicillin, $20.7 \%$ to oxytetracycline, $17.3 \%$ to chloramphenicol, and $15.5 \%$ to gentamicin. A small number of isolates were

Table 1 Antibiotic susceptibility frequencies of 76 Pasteurella multocida type B isolates

\begin{tabular}{|c|c|c|c|c|c|c|c|c|c|}
\hline \multirow{3}{*}{$\begin{array}{l}\text { Antimicrobial } \\
\text { agent }\end{array}$} & \multicolumn{9}{|c|}{ Susceptibility frequencies (\%) to individual antibiotic } \\
\hline & \multicolumn{3}{|c|}{ Swine $(n=58)$} & \multicolumn{3}{|c|}{ Cattle $(n=18)$} & \multicolumn{3}{|c|}{ Total $(n=76)$} \\
\hline & $S$ & I & $\mathrm{R}$ & S & I & $\mathrm{R}$ & $S$ & I & $\mathrm{R}$ \\
\hline ENR & 86.2 & 6.9 & 6.9 & 94.4 & 5.6 & 0 & 88.2 & 6.6 & 5.3 \\
\hline CEF & 98.3 & 1.7 & 0 & 100 & 0 & 0 & 98.7 & 1.3 & 0 \\
\hline GEN & 84.5 & 0 & 15.5 & 100 & 0 & 0 & 88.2 & 0 & 11.8 \\
\hline C & 81.0 & 1.7 & 17.3 & 100 & 0 & 0 & 85.5 & 1.3 & 13.2 \\
\hline LIN & 0 & 0 & 100 & 5.6 & 0 & 94.4 & 1.3 & 0 & 98.7 \\
\hline PEN & 72.4 & 0 & 27.6 & 72.2 & 22.2 & 5.6 & 72.4 & 5.3 & 22.4 \\
\hline OXY & 77.6 & 1.7 & 20.7 & 100 & 0 & 0 & 82.9 & 1.3 & 15.8 \\
\hline TE & 58.6 & 12.1 & 29.3 & 94.4 & 5.6 & 0 & 67.1 & 10.5 & 22.4 \\
\hline ERY & ND & ND & ND & ND & ND & ND & ND & ND & ND \\
\hline NEO & ND & ND & ND & ND & ND & ND & ND & ND & ND \\
\hline
\end{tabular}

C Chloramphenicol; CEF Ceftiofur; ENR Enrofloxacin; ERY Erythromycin; GEN Gentamicin; I Intermediate; LIN Lincomycin; ND Non-determined value; NEO Neomycin; OXY Oxytetracycline; PEN Penicillin; $S$ Susceptible; $R$ Resistant; TE Tetracycline. 
Table 2 MIC value distribution of Pasteurella multocida type B isolates derived from swine $(n=58)$

\begin{tabular}{|c|c|c|c|c|c|c|c|c|c|c|c|c|c|c|}
\hline \multirow[t]{2}{*}{ Break point } & \multirow[t]{2}{*}{$\mathrm{Ab}$} & \multicolumn{10}{|c|}{ Number of isolates for each MIC ( $\mu \mathrm{g} / \mathrm{mL})$} & \multirow[t]{2}{*}{$\mathrm{MIC}_{50}$} & \multirow[t]{2}{*}{$\mathrm{MIC}_{90}$} & \multirow[t]{2}{*}{$\% R$} \\
\hline & & $\leq 0.03$ & 0.06 & 0.125 & 0.25 & 0.5 & 1 & 2 & 4 & 8 & $\geq 16$ & & & \\
\hline$\geq 1$ & ENR & 45 & 2 & 2 & 1 & 4 & 3 & 0 & 1 & 0 & 0 & $\leq 0.03$ & 0.5 & 6.9 \\
\hline$\geq 8$ & CEF & 39 & 3 & 0 & 1 & 4 & 7 & 3 & 1 & 0 & 0 & $\leq 0.03$ & 1 & 0 \\
\hline$>8$ & GEN & 0 & 0 & 0 & 0 & 0 & 3 & 11 & 16 & 19 & 9 & 4 & $\geq 16$ & 15.5 \\
\hline$\geq 32$ & $C$ & 0 & 0 & 0 & 2 & 29 & 6 & 3 & 3 & 4 & $>11^{c}$ & 0.5 & $\geq 16$ & 17.2 \\
\hline$>2$ & LIN & 0 & 0 & 0 & 0 & 0 & 0 & 0 & 0 & 6 & 52 & $\geq 16$ & $\geq 16$ & 100 \\
\hline$\geq 1$ & PEN & 10 & 12 & 17 & 3 & 0 & 0 & 16 & 0 & 0 & 0 & 0.125 & 2 & 27.6 \\
\hline$\geq 2^{\mathrm{a}}$ & OXY & 4 & 3 & 6 & 26 & 6 & 1 & 2 & 1 & 9 & 0 & 0.25 & 8 & 20.7 \\
\hline$\geq 2$ & TE & 3 & 0 & 6 & 16 & 9 & 7 & 7 & 3 & 7 & 0 & 0.5 & 8 & 29.3 \\
\hline ND & ERY & 0 & 0 & 2 & 2 & 3 & 8 & 1 & 8 & 0 & 34 & $\geq 16$ & $\geq 16$ & ND \\
\hline$N D^{b}$ & NEO & 0 & 0 & 0 & 0 & 0 & 1 & 6 & 14 & 20 & 17 & 8 & $\geq 16$ & ND \\
\hline
\end{tabular}

${ }^{a}$ breakpoint reference value for tetracycline; ${ }^{b}$ breakpoint value for $P$. multocida derived from dogs; ${ }^{\mathrm{c}} \mathrm{MIC}$ value $=32 \mu \mathrm{g} / \mathrm{mL}$. Ab Antibiotic; $\mathrm{C}$ Chloramphenicol; $C E F$ Ceftiofur; ENR Enrofloxacin; ERY Erythromycin; GEN Gentamicin; LIN Lincomycin; MIC Minimum inhibitory concentration; ND Non-determined value for $P$. multocida according to the Clinical and Laboratory Standards Institute (CLSI; 2013); NEO Neomycin; OXY Oxytetracycline; PEN Penicillin; TE Tetracycline

resistant to enrofloxacin (6.9\%) while no resistance to ceftiofur was detected. The resistance rates of penicillin $(p=0.05)$ and oxytetracycline $(p=0.035)$ were significantly higher in swine than in cattle. There was no statistical difference in the rest of antimicrobial agents tested between both host species.

The resistance rates to erythromycin and neomycin could not be determined in any of the isolates because the break points of these drugs for $P$. multocida isolates have not yet been defined in the Clinical and Laboratory Standards Institute (CLSI) criteria. The MIC values for porcine and bovine isolates ranged between 0.125 and $\geq$ $16 \mu \mathrm{g} / \mathrm{mL}$ for erythromycin, and most swine isolates (34/ 58) had a MIC value $\geq 16 \mu \mathrm{g} / \mathrm{mL}$. For neomycin, the MIC values of porcine isolates were between 1 and $\geq 16 \mu \mathrm{g} /$ $\mathrm{mL}$ and were from 0.06 to $8 \mu \mathrm{g} / \mathrm{mL}$ for bovine isolates. Interestingly, swine and bovine isolates had the same $\mathrm{MIC}_{50}$ values for enrofloxacin $(\leq 0.03 \mu \mathrm{g} / \mathrm{mL})$, ceftiofur $(\leq 0.03 \mu \mathrm{g} / \mathrm{mL})$, chloramphenicol $(0.5 \mu \mathrm{g} / \mathrm{mL})$, lincomycin $(\geq 16 \mu \mathrm{g} / \mathrm{mL})$, and oxytetracycline $(0.25 \mu \mathrm{g} / \mathrm{mL})$. However, the $\mathrm{MIC}_{50}$ was higher in swine isolates than in bovine isolates for gentamicin, penicillin, erythromycin, and neomycin. More marked differences were found in the $\mathrm{MIC}_{90}$ values, which were higher for the porcine isolates than for the bovine ones, except for lincomycin and erythromycin $(\geq 16 \mu \mathrm{g} / \mathrm{mL}$ in both hosts). The distribution of the antimicrobial susceptibility patterns for $P$. multocida type B isolates from swine and cattle are summarized in Table 4.

Of note, all the isolates from both species were resistant at least to one of the 10 drugs we tested. While no MDR strains were found for the bovine isolates, $25.86 \%$ of the porcine isolates were multiresistant $(p=0.016)$. Importantly, lincomycin and penicillin resistance were present in all the MDR patterns we identified.

Table 3 MIC value distribution of Pasteurella multocida type B isolates derived from cattle $(n=18)$

\begin{tabular}{|c|c|c|c|c|c|c|c|c|c|c|c|c|c|c|}
\hline \multirow[t]{2}{*}{ Break point } & \multirow[t]{2}{*}{$\mathrm{Ab}$} & \multicolumn{10}{|c|}{ Number of isolates for each MIC $(\mu \mathrm{g} / \mathrm{mL})$} & \multirow[t]{2}{*}{$\mathrm{MIC}_{50}$} & \multirow[t]{2}{*}{$\mathrm{MIC}_{90}$} & \multirow[t]{2}{*}{$\% R$} \\
\hline & & $\leq 0.03$ & 0.06 & 0.125 & 0.25 & 0.5 & 1 & 2 & 4 & 8 & $\geq 16$ & & & \\
\hline$\geq 1$ & ENR & 16 & 1 & 0 & 0 & 1 & 0 & 0 & 0 & 0 & 0 & $\leq 0.03$ & 0.06 & 0 \\
\hline$\geq 8$ & CEF & 16 & 0 & 1 & 0 & 0 & 1 & 0 & 0 & 0 & 0 & $\leq 0.03$ & 0.125 & 0 \\
\hline$>8$ & GEN & 1 & 0 & 0 & 1 & 0 & 0 & 10 & 6 & 0 & 0 & 2 & 4 & 0 \\
\hline$\geq 32$ & $C$ & 0 & 0 & 0 & 0 & 17 & 1 & 0 & 0 & 0 & 0 & 0.5 & 0.5 & 0 \\
\hline$>2$ & LIN & 0 & 0 & 0 & 0 & 0 & 0 & 1 & 0 & 6 & 11 & $\geq 16$ & $\geq 16$ & 94.4 \\
\hline$\geq 1$ & PEN & 1 & 10 & 1 & 1 & 4 & 1 & 0 & 0 & 0 & 0 & 0.06 & 0.5 & 5.6 \\
\hline$\geq 8$ & OXY & 2 & 2 & 1 & 10 & 3 & 0 & 0 & 0 & 0 & 0 & 0.25 & 0.5 & 0 \\
\hline$\geq 8$ & TE & 1 & 0 & 2 & 6 & 1 & 5 & 2 & 1 & 0 & 0 & 0.25 & 2,0 & 0 \\
\hline ND & ERY & 0 & 0 & 1 & 6 & 3 & 0 & 0 & 0 & 0 & 8 & 0.5 & $\geq 16$ & ND \\
\hline ND & NEO & 0 & 1 & 0 & 0 & 1 & 0 & 0 & 14 & 2 & 0 & 0.4 & 8 & ND \\
\hline
\end{tabular}

${ }^{\mathrm{a}}$ breakpoint reference value for tetracycline; ${ }^{\mathrm{b}}$ breakpoint value for $P$. multocida derived from dogs. Ab Antibiotic; C Chloramphenicol; CEF Ceftiofur; ENR Enrofloxacin; ERY Erythromycin; GEN Gentamicin; LIN Lincomycin; MIC Minimum inhibitory concentration; ND Non-determined value for $P$. multocida according to the Clinical and Laboratory Standards Institute (CLSI; 2013); NEO Neomycin; OXY Oxytetracycline; PEN Penicillin; TE Tetracycline 
Table 4 Patterns of antimicrobial resistance of P. multocida isolates from swine and cattle

\begin{tabular}{|c|c|c|c|c|}
\hline Patterns of antimicrobial resistance & Antibiotic classes $(n)$ & Porcine isolates $(n)$ & Bovine isolates $(n)$ & Total Isolates (n) \\
\hline LIN & 1 & 37 & 14 & 51 \\
\hline PEN & 1 & 0 & 1 & 1 \\
\hline C-LIN & 2 & 1 & 0 & 1 \\
\hline ENR-LIN & 2 & 1 & 0 & 1 \\
\hline LIN-PEN & 2 & 1 & 0 & 1 \\
\hline LIN-TE & 2 & 3 & 3 & 6 \\
\hline GEN-LIN-PEN & 3 & 1 & 0 & 1 \\
\hline LIN-PEN-TE & 3 & 2 & 0 & 2 \\
\hline LIN-PEN-OXY-TE ${ }^{a}$ & 3 & 2 & 0 & 2 \\
\hline C-LIN-PEN-OXY-TE ${ }^{a}$ & 4 & 2 & 0 & 2 \\
\hline GEN-LIN-PEN-OXY-TE ${ }^{a}$ & 4 & 1 & 0 & 1 \\
\hline GEN-C-LIN-PEN-OXY-TE ${ }^{a}$ & 5 & 6 & 0 & 6 \\
\hline ENR-GEN-C-LIN-PEN-OXY-TE ${ }^{a}$ & 6 & 1 & 0 & 1 \\
\hline
\end{tabular}

a OXY-TE: OXY and TE belong to the same group of antibiotics. C Chloramphenicol; CEF Ceftiofur; ENR Enrofloxacin; ERY Erythromycin; GEN Gentamicin; LIN Lincomycin; NEO Neomycin; OXY Oxytetracycline; PEN Penicillin; TE Tetracycline

\section{Discussion}

To the best of our knowledge, this study represents the first research performed in Europe about the antimicrobial susceptibility of capsular type B P. multocida derived from clinical samples from pigs and cattle affected with acute septicemia. However, the antimicrobial susceptibility of capsular types A and D from porcine isolates have been previously discussed for Spain [24, 25], China [18], Brazil [26], and Korea [27]. In addition, other authors have studied antimicrobial resistance rates in $P$. multocida isolates from cattle in Europe [28] and the United States [29]. All of these previous data are summarized in Table 5.

The sale of veterinary antibiotics in Spain is among the highest in Europe [30]. To promote the prudent use of antibiotics, antimicrobial resistances must first be detected and monitored. This data must then be made available to veterinarians so that they can implement effective therapies. Furthermore, it is important to define the antimicrobial susceptibility profile of type B P. multocida so that acute pasteurellosis can be treated as early as possible with effective antibiotics.

In our study, 18 P. multocida type B isolates from diseased cattle were highly susceptible to all the antibiotics we tested, except for lincomycin $(94.4 \%$ of the isolates were resistant). The MIC values for this antimicrobial agent varied from 2 to $\geq 16 \mu \mathrm{g} / \mathrm{mL}$ and the $\mathrm{MIC}_{50}$ and MIC $_{90}$ were both $\geq 16 \mu \mathrm{g} / \mathrm{mL}$. These values exceeded the break point $(>2 \mu \mathrm{g} / \mathrm{mL})$, indicating the presence of antimicrobial resistance to this drug. Compared to our work, other authors who studied $P$. multocida isolated from cases of pneumonia from across Europe [28], found higher MIC values (between 16 and $64 \mu \mathrm{g} / \mathrm{mL}$ ) in bovine isolates, with the MIC for most isolates being $32 \mu \mathrm{g} / \mathrm{mL}$.
Timsit et al. [29] also described higher resistance rates in P. multocida isolates from a Canadian feedlot (83\% of these isolates were resistant to oxytetracycline), both from healthy cattle and those affected with bovine respiratory disease. However, oxytetracycline and other antibiotics were used at this feedlot before the enrollment, which may help to explain these results. Even so, in agreement with our results, these authors found no resistances to ceftiofur or enrofloxacin. The absence or low levels of antibiotic resistances we found for type B bovine $P$. multocida in this study might be expected because this pathogen has only recently emerged in cattle in Spain [13], meaning that this type have been subjected to very little selective pressure to date. In addition, so far, P. multocida type B has only been detected in animals reared in extensive systems.

The same as our findings in cattle, lincomycin was completely ineffective against type B $P$. multocida derived from porcine isolates. The MIC values of this drug varied from 8 to $\geq 16 \mu \mathrm{g} / \mathrm{mL}$ in pigs and the $\mathrm{MIC}_{50}$ and $\mathrm{MIC}_{90}$ were both $\geq 16 \mu \mathrm{g} / \mathrm{mL}$. Lincomycin resistance has previously been reported in P. multocida type A or D isolates from pigs in China [18] with $96.6 \%$ of isolates resistant to this antibiotic and an $\mathrm{MIC}_{50}$ of $8 \mu \mathrm{g} / \mathrm{mL}$ and $\mathrm{MIC}_{90}$ of $32 \mu \mathrm{g} / \mathrm{mL}$ reported. Lincomycin has not yet been tested in this context in Spain, although some authors have researched resistance to clindamycin, an antibiotic from the same family of antimicrobials. PetrocchiRilo et al. [25] found $96.9 \%$ resistance (31/32 isolates) to clindamycin, while El Garch et al. [28] described in Europe MIC values to lincomycin between 4 and $64 \mu \mathrm{g} / \mathrm{mL}$ in porcine isolates (the mode value was $32 \mu \mathrm{g} / \mathrm{mL}$ ). According to the break point specified by the Clinical and Laboratory Standards Institute (CLSI) for lincomycin, all 


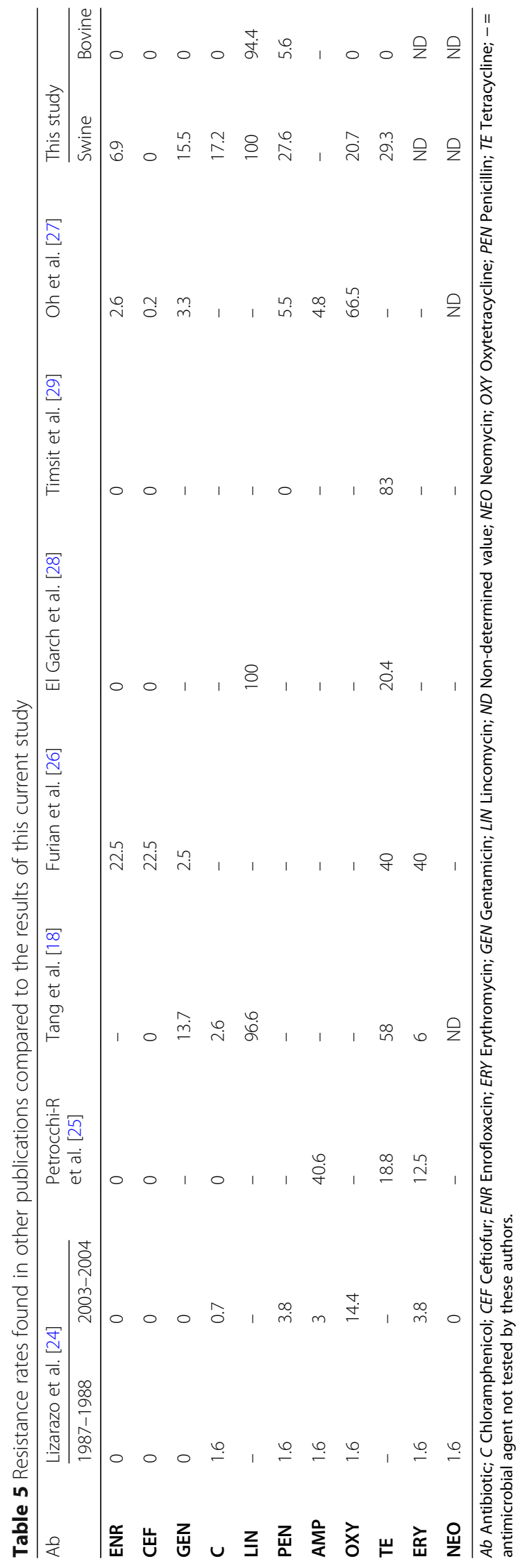


isolates from El Garch et al. [28] would have been classified as resistant. The low activity of lincosamides against Pasteurellaceae is well known [31] and the selection of this antimicrobial in the study reflects in the number of MDR patterns identified. According to our data and these previously published results, the use of antimicrobials in the lincosamides family is unlikely to effectively treat cattle or pigs affected with $P$. multocida and thus, is not recommended.

In Spain, the rate of resistance to tetracyclines did not excessively increase from 2004 (14.4\%) to 2018 (18.8\%) for type A or D P. multocida isolates from pigs [25]. Here, we found that 29.3 and $20.7 \%$ of $P$. multocida type $B$ isolates from pigs were resistant to tetracycline and oxytetracycline, respectively. According to El Garch et al., the resistance rate of $P$. multocida isolates to tetracycline in Europe and Australia (between 11.5 and $32.2 \%)$ were the highest from among several antimicrobials tested [28]. Higher resistance values have been obtained for type A or D P. multocida from swine for tetracycline in China (58\% [18]; and oxytetracycline in Korea (66.5\% [27]; which may be related to the heavy use of antimicrobials in these countries compared to the European Union, especially in the pig industry [27]. Furian et al. [26] also found high resistance to tetracycline in Brazil with $40 \%$ of the type A or D P. multocida isolates they had derived from pigs being resistant to this drug.

B-lactams are widely used in the treatment and prevention of swine respiratory tract diseases. This group of antibiotics showed high efficacy ( $>96 \%$ susceptibility) against $P$. multocida type A or D from swine 15 years ago in Spain [24]. However, their wide use has exerted selective resistance pressure on pathogens so that $P$. multocida isolated from pigs in Spain currently show resistance to penicillin and ampicillin in $27.6 \%$ (in this study) and $40.6 \%$ [25] of cases, respectively. The percentage of $P$. multocida type $\mathrm{B}$ isolates resistant to penicillin may be lower because acute septicemia has appeared in Spain relatively recently. In contrast, ß-lactams remain effective in Korea where, according to one report, only $5.5 \%$ of $P$. multocida isolates from pigs were resistant to penicillin and $4.8 \%$ were resistant to ampicillin [27].

Chloramphenicol may cause adverse effects in humans and it is only recommended when safer antimicrobials cannot be used. Though previous authors found a high level of susceptibility $(<3 \%$ of isolates were resistant) to this drug $[18,24,25,32]$, in our study $17.3 \%$ of $P$. multocida type B isolates from swine were resistant to it. In agreement with our results, a study carried out in Korea indicated that $18.5 \%$ of type A or D P. multocida isolates from pigs were resistant to florfenicol [27]. This drug, a phenicol used widely in veterinary medicine to treat pneumonia caused by $P$. multocida, belongs to the same antimicrobial group as chloramphenicol. Indeed, previous authors have found florfenicol to be highly effective [33]. Likewise, gentamicin exhibited moderate activity against the swine isolates we tested in this study $(84.5 \%$ were susceptible). Similar results were reported by Tang et al. [18] who found $86.3 \%$ of their isolates were susceptible to this antibiotic, although other authors have described lower resistance rates $(<3.3 \%)$ to gentamicin in $P$. multocida isolates [24, 26, 27, 32].

Enrofloxacin and ceftiofur seemed to have the highest in vitro activity against the isolates we tested: only 4 of $58(6.9 \%)$ of the P. multocida type B isolates from pigs that we tested were not susceptible to enrofloxacin, and all of them were vulnerable to ceftiofur. This finding is in accordance with a situation that has remained constant in Spain since 1987 [24, 25]. Additionally, research carried out in Europe between 2009 and 2012 with total of $152 \mathrm{P}$. multocida isolates from pigs failed to find any that were resistant to ceftiofur or enrofloxacin [28]. Moreover, high susceptibility rates to these drugs have been reported for $P$. multocida isolates from pigs in China or Korea [18, 27]. However, Brazilian authors reported that in both cases, $22.5 \%$ of their swine isolates were resistant to enrofloxacin and ceftiofur [26]. Although ceftiofur, enrofloxacin, and gentamicin are highly effective antibiotics against $P$. multocida, according to the OIE and WHO, cephalosporins (3rd, 4th, and 5th generation), macrolides, and aminoglycosides are critically important antibiotics for human medicine and animal health [22, 23]. Therefore, their use is only recommended as an emergency treatment in the early stages of HS, until the susceptibility test results are known.

We were unable to determine the resistance rates of erythromycin and neomycin in this study because no break points for $P$. multocida have been defined by the CLSI for these drugs. The MIC values for erythromycin for the isolates tested from both hosts in this research were between 0.125 and $\geq 16 \mu \mathrm{g} / \mathrm{mL}$, and in most cases $(42 / 76)$ were $\geq 16 \mu \mathrm{g} / \mathrm{mL}$. Tang et al. [18] used $8 \mu \mathrm{g} / \mathrm{mL}$ as the break point for this macrolide; thus, applying this break point to the type B P. multocida isolates we used in this current study would have meant that $58.6 \%$ of those from pigs and $44.4 \%$ from cattle would have been classified as resistant to erythromycin. Some authors have reported moderate susceptibility to this drug [25, 32] and in other research, $40 \%$ of $P$. multocida isolates from pigs were resistant to erythromycin [26]. Others tested the susceptibility of 25 swine $P$. multocida type B isolates against tildipirosin and found that this macrolide inhibited the growth of more than $80 \%$ of the isolates [34]. In our study, the $\mathrm{MIC}_{50}$ and $\mathrm{MIC}_{90}$ values for erythromycin (both $\geq 16 \mu \mathrm{g} / \mathrm{mL}$ ) were higher than those described by previous authors at $2 \mu \mathrm{g} / \mathrm{mL}$ and $4 \mu \mathrm{g} / \mathrm{mL}$ for $\mathrm{MIC}_{50}$ and $\mathrm{MIC}_{90}$, respectively $[18,24]$. The MIC values for neomycin in this current study were between 1 and $\geq 16 \mu \mathrm{g} / \mathrm{mL}$ for swine 
isolates and 0.006 and $8 \mu \mathrm{g} / \mathrm{mL}$ for bovine isolates, and the $\mathrm{MIC}_{50}$ and $\mathrm{MIC}_{90}$ of the swine isolates were similar to those described previously in type A or D P. multocida isolates from swine [18, 24, 27].

MDR has increased over time, partly because of the widespread use of antimicrobials in human and veterinary medicine and antibiotic additives used in animal feed [18]. Additionally, the horizontal transfer of genes through different bacterial species promotes MDR development [19]. Lizarazo et al. [24] reported that in Spain, 7.93\% of isolates were resistant to at least four antimicrobials between 1987 and 1988 and that this had risen to $61.9 \%$ of those studied between 2003 and 2004. In China, others have described an increase in the prevalence of isolates resistant to more than five antibiotics (from $47.8 \%$ in 2003 to $97.1 \%$ in 2007) or more than seven antibiotics (from 16.2\% in 2003 to $62.8 \%$ in 2007) [18]. Of note, there was a sharp increase in the prevalence of MDR among capsular types A and D $P$. multocida isolates from pigs. In this current study on capsular type B isolates, while no MDR could be found in isolates from cattle, $25.86 \%$ of those from pigs were resistant to three or more antibiotic classes.

Perhaps the high rate of resistance and number of MDR isolates found for swine in our study can be explained by the more intensive use of antibiotics in the pig industry compared to the cattle industry in Spain. The official European JIACRA (joint inter-agency antimicrobial consumption and resistance analysis) report indicates that while antibiotic consumption for cattleexpressed in $\mathrm{mg} / \mathrm{PCU}$ (population correction unit)-in Spain was around $900 \mathrm{mg} / \mathrm{PCU}$ between 2010 and 2016, in pigs it was more than $3500 \mathrm{mg} / \mathrm{PCU}$. This report also states that $58.51 \%$ of $B$-lactams were used in the pig industry while $28.43 \%$ were used in ruminants; in the case of tetracyclines, $58 \%$ were used in the pig industry and only $14 \%$ in ruminants [21]. In agreement with other studies which highlighted tetracycline and lincomycin as the antimicrobials most commonly involved in resistance patterns [18, 27], lincomycin, penicillin, and tetracycline were most frequently included in the resistance patterns we observed here.

\section{Conclusions}

In this study we report the lower in vitro resistance rates of P. multocida type B isolates from cattle to several antibiotics, as well as a lower prevalence of MDR in bovine isolates, compared to those isolated from pigs. This can be explained by the extensive use of antibiotics in the pig industry in Spain. Lincosamides showed poor activity against all types of $P$. multocida isolates and therefore, is not recommended for treating diseases in cattle or pigs caused by this pathogen. Based on the susceptibility of $P$. multocida type B isolates in this study, the use of ceftiofur, enrofloxacin, or gentamicin is preferable as an emergency treatment in the early stages of HS until susceptibility test results are known, and thereafter, therapeutic or metaphylactic treatments with tetracycline, oxytetracycline, penicillin, or chloramphenicol should be prioritized accordingly. The rapid increase in P. multocida isolate resistance against important groups of antimicrobial agents indicates that more attention should be paid to disease prevention and the responsible use of antibiotics, especially those which are important to human health, in order to limit the emergence and spread of antibiotic-resistant bacteria in humans and animals.

\section{Methods}

\section{Bacterial isolates and identification}

A total of 76 P. multocida type B isolates (58 porcine and 18 bovine) were evaluated in this study. The isolates were collected between 2009 and 2015 from different outbreaks of acute septicemic pasteurellosis that caused a high mortality rate in pigs and cattle located in 11 different extensively reared systems. Only isolates identified as $P$. multocida type B were assessed in the study. For this purpose, samples were plated on blood agar $\left(\mathrm{Oxoid}^{\circ}\right)$ supplemented with $5 \%$ defibrinated sheep blood and incubated at $37^{\circ} \mathrm{C}$ for $24 \mathrm{~h}$ under microaerobic conditions. The initial identification was done based on phenotypic and biochemical properties and was further confirmed by detection of the kmt1 gene in a species-specific PCR assay [35]. The capsular type was determined using the PCR assay protocol described by Townsend et al. [36], and the biovar was assessed based on the production of the enzyme ornithine decarboxylase, urease activity, and fermentation of seven different carbohydrates [37, 38].

\section{Antimicrobial susceptibility evaluation}

All $P$. multocida type B isolates were tested for their antimicrobial susceptibility based on their MIC. Staphylococcus aureus (ATCC 29213 [39]; was used as a quality-control strain, and its MIC value ranges are shown in Table 6.

Table 6 MIC value ranges for the ATCC ${ }^{\circledR} 29,213$ Staphylococcus aureus quality control strain

\begin{tabular}{ll}
\hline Antibiotic & Acceptable MIC value range $(\mu \mathrm{g} / \mathrm{mL})$ \\
\hline Erythromycin & $0.25-1$ \\
Lincomycin & ND \\
Neomycin & ND \\
Penicillin & $0.25-2$ \\
Oxytetracycline & $0.12-1^{\text {a }}$ \\
Tetracycline & $0.12-1$ \\
Gentamicin & $0.12-1$ \\
Enrofloxacin & $0.03-12$ \\
Ceftiofur & $0.25-1$ \\
Chloramphenicol & $2-16$ \\
\hline
\end{tabular}

${ }^{a}$ Reference value for tetracycline. ND non-determined value according to the Clinical and Laboratory Standards Institute (CLSI; 2013) 
The assays were carried out according to the CLSI VET01-A4 performance standards [39]. This quantitative, in vitro method tests susceptibility to antimicrobials at different dilutions in microdilution plates inoculated by adding $100 \mu \mathrm{l}$ of each isolate. In this study we tested 10 antimicrobial agents (Vetranal, Sigma-Aldrich ${ }^{\circ}$ ): erythromycin, lincomycin, neomycin, penicillin, oxytetracycline, tetracycline, gentamicin, enrofloxacin, ceftiofur, and chloramphenicol. These drugs are widely used by field veterinarians in pigs and cattle and were recommended on the technical hemorrhagic septicemia card provided by the OIE [40].

The inoculum from each isolate was prepared from colonies that had been plated on blood agar; isolates with a spectrophotometric absorbance at $625 \mathrm{~nm}$ of 0.08 to 0.13 were used [39]. The inoculum was diluted on a microplate panel and these were fixed with adhesive seals and incubated at $35^{\circ} \mathrm{C} \pm 2{ }^{\circ} \mathrm{C}$ for $12 \pm 2 \mathrm{~h}$. The MIC was defined as the first dilution at which no visible growth of the isolate was detected in the presence of the antimicrobial being tested. The MICs for lincomycin, penicillin, oxytetracycline, tetracycline, gentamicin, enrofloxacin, and ceftiofur were interpreted using the break points provided by the CLSI guidelines [41]. No break point values for $P$. multocida were available for erythromycin or neomycin (Tables 2 and 3). P. multocida isolates resistant to three or more different antimicrobial classes were defined as MDR isolates [42]. The $\mathrm{MIC}_{50}$ and $\mathrm{MIC}_{90}$ were the MICs that inhibited the growth of 50 or $90 \%$ of the isolates, respectively.

\section{Statistical analysis}

Statistical testing was performed with the SPSS software package, version 25.0 (IBM Corp., Armonk, NY). The resistance rates of isolates from both hosts studied as well as MDR isolates were compared using $X^{2}$ tests. In any category where $n \leq 5$, Fisher's exact test was used. In all cases, $p$ values of $\leq 0.05$ were considered statistically significant.

\section{Abbreviations \\ AGISAR: Advisory group on integrated surveillance of antimicrobial resistance; CLSI: Clinical and laboratory standards institute; HS: Hemorrhagic septicemia; MDR: Multidrug resistant; MIC: Minimum inhibitory concentration; $\mathrm{MIC}_{50}$ : MIC that inhibited the growth of $50 \%$ of the isolates; $\mathrm{MIC}_{90}$ : MIC that inhibited the growth of $90 \%$ of the isolates; OIE: World organization for animal health; WHO: World health organization.}

\section{Acknowledgements}

The authors would like to extend their thanks to all the farmers and clinical veterinarians involved for providing samples from diseased animals, as well as the staff at the Cordoba University Animal Health Department.

\section{Authors' contributions}

Conceived and designed the study: CB, AC, IGB and IC. Collected the data: $C B, D C$, and IC. Performed the analysis: $C B, I G B$, and IC. Wrote the first draft: $C B, I C$. Reviewed the paper: MAA, CB, IC and gave final approval: All the authors.

\section{Funding}

This research did not receive any specific grant from funding agencies in the public, commercial, or not-for-profit sectors.

\section{Availability of data and materials}

All data supporting these research findings are included within the manuscript. The databases (without personally identifiable information) are available from the corresponding author upon request.

Ethics approval and consent to participate

Not applicable.

\section{Consent for publication}

Not applicable.

\section{Competing interests}

The authors declare that they have no competing interests.

\section{Author details}

'Department of Animal Health (AGR-149). Campus of International Agri-Food Excellence CeiA3, University of Córdoba, Rabanales University Campus, 14071 Córdoba, Spain. ${ }^{2}$ Department of Bromatology. Campus of International Agri-Food Excellence CeiA3, University of Córdoba, Rabanales University Campus, 14071 Córdoba, Spain.

Received: 31 March 2019 Accepted: 23 June 2020

Published online: 30 June 2020

\section{References}

1. Harper M, Boyce JD, Adler B. Pasteurella multocida pathogenesis: 125 years after Pasteur. FEMS Microbiol Lett. 2006;265(1):1-10.

2. Glimour NJ. Pasteurellosis in sheep. Vet Rec. 1978;102(5):100-2.

3. Rimler RB, Brogden KA. Pasteurella multocida isolated from rabbits and swine: serologic types and toxin production. Am J Vet Res. 1986;47(4):730-7.

4. De Alwis MC. Haemorrhagic septicaemia-a general review. Br Vet J. 1992; 148(2):99-112.

5. Ewers C, Lubke-Becker A, Bethe A, Kiessling S, Filter M, Wieler LH. Virulence genotype of Pasteurella multocida strains isolated from different hosts with various disease status. Vet Microbiol. 2006;114(3-4):304-17.

6. Townsend KM, O'Boyle D, Phan TT, Hanh TX, Wijewardana TG, Wilkie I, et al. Acute septicaemic pasteurellosis in Vietnamese pigs. Vet Microbiol. 1998; 63(2-4):205-15.

7. Verma ND. Pasteurella multocida $B: 2$ in haemorrhagic septicaemia outbreak in pigs in India. Vet Rec. 1988;123(2):63.

8. Gamage LNA, Wijewardana TG, Bastiansz HLG, Vipulasiri AA. An outbreak of acute pasteurellosis in swine caused by serotype B:2 in Sri Lanka. Sri Lanka Vet J. 1995:42:15-9.

9. Mackie JT, Barton M, Kettlewell J. Pasteurella multocida septicaemia in pigs. Aust Vet J. 1992;69(9):227-8.

10. Borge C, Barranco I, Márquez del Cid JM, Rodríguez-Guerra MA, Carbonero A, Carrasco L, et al. In: Proceeding of the 3sr European Simposium of porcine health and management (ESPHM). Faculty of Veterinary Medicine. Espoo, Finland: University of Helsinki; 2011.

11. Cardoso-Toset F, Gomez-Laguna J, Callejo M, Vela Al, Carrasco L, FernandezGarayzabal JF, et al. Septicaemic pasteurellosis in free-range pigs associated with an unusual biovar 13 of Pasteurella multocida. Vet Microbiol. 2013: 167(3-4):690-4.

12. Risco D, Fernández-Llario P, Cuesta JM, García-Jiménez WL, Gil M, Gonçalves $P$, et al. Fatal outbreak of systemic pasteurellosis in a wild boar (Sus scrofa) population from Southwest Spain. J Vet Diagn Investig. 2013;25(6):791-4.

13. Cuevas I, Carbonero A, Cano D, Pacheco I, Marín JC, Borge C, et al. First outbreak of bovine haemorrhagic septicaemia caused by Pasteurella multocida type B in Spain. Acta Vet Hung. 2020. https://doi.org/10.1556/004 2020.00014

14. Ujvári B, Szeredi L, Pertl L, Tóth G, Erdélyi K, Jánosi S, et al. First detection of Pasteurella multocida type B:2 in Hungary associated with systemic pasteurellosis in backyard pigs. Acta Vet Hung. 2015;63(2):141-56.

15. Magyar T, Ujvári B, Szeredi L, Virsinger N, Albert E, Német Z, et al. Reemergence of bovine haemorrhagic septicaemia in Hungary. Acta Vet Hung. 2017:65(1):41-9. 
16. Shivachandra SB, Viswas KN, Kumar AA. A review of hemorrhagic septicemia in cattle and buffalo. Animal health research reviews / Conference of Research Workers in Animal Diseases. 2011;12(1):67-82.

17. Kehrenberg C, Schulze-Tanzil G, Martel JL, Chaslus-Dancla E, Schwarz S. Antimicrobial resistance in Pasteurella and Mannheimia: epidemiology and genetic basis. Vet Res. 2001;32(3-4):323-39.

18. Tang X, Zhao Z, Hu J, Wu B, Cai X, He Q, et al. Isolation, antimicrobial resistance, and virulence genes of Pasteurella multocida strains from swine in China. J Clin Microbiol. 2009;47(4):951-8.

19. Walsh C, Fanning S. Antimicrobial resistance in foodborne pathogens-a cause for concern? Curr Drug Targets. 2008;9(9):808-15.

20. WHO. Global action plan on antimicrobial resistance. 2015. http://www. wpro.who.int/entity/drug_resistance/resources/global_action_plan_eng.pdf.

21. Joint Interagency Antimicrobial Consumption and Resistance Analysis (JIACRA-SPAIN) Report. First joint report on the integrated analysis of the consumption of antimicrobial agents and occurrence of antimicrobial resistance. Spain. 2018. http://www.resistenciaantibioticos.es/es/ publicaciones/informe-jiacra-espana.

22. WHO. Critically important antimicrobials for human medicine, 5th revision 2016. https://www.who.int/foodsafety/publications/antimicrobials-fifth/en/.

23. OIE. List of antimicrobial agents of veterinary importance. 2019. https:// www.oie.int/fileadmin/Home/eng/Our_scientific_expertise/docs/pdf/AMR/ A_OIE_List_antimicrobials_July2019.pdf.

24. Lizarazo YA, Ferri EF, de la Fuente AJ, Martín CB. Evaluation of changes in antimicrobial susceptibility patterns of Pasteurella multocida subsp multocida isolates from pigs in Spain in 1987-1988 and 2003-2004. Am J Vet Res. 2006; 67(4):663-8.

25. Petrocchi-Rilo M, Gutiérrez-Martín CB, Méndez-Hernández Jl, Rodríguez-Ferri EF, Martínez-Martínez S. Antimicrobial resistance of Pasteurella multocida isolates recovered from swine pneumonia in Spain throughout 2017 and 2018. Vet Anim Sci. 2019;7:100044.

26. Furian TQ, Borges KA, Laviniki V, Rocha SL, de Almeida CN, Do Nascimento VP, et al. Virulence genes and antimicrobial resistance of Pasteurella multocida isolated from poultry and swine. Braz J Microbiol. 2016;47(1):210-6.

27. Oh YH, Moon DC, Lee YJ, Hyun BH, Lim SK. Antimicrobial resistance of Pasteurella multocida strains isolated from pigs between 2010 and 2016. Vet Rec Open. 2018;5(1):e000293.

28. El Garch F, de Jong A, Simjee S, Moyaert H, Klein U, Ludwig C, et al. Monitoring of antimicrobial susceptibility of respiratory tract pathogens isolated from diseased cattle and pigs across Europe, 2009-2012: VetPath results. Vet Microbiol. 2016;194:11-22.

29. Timsit E, Hallewell J, Booker C, Tison N, Amat S, Alexander TW. Prevalence and antimicrobial susceptibility of Mannheimia haemolytica, Pasteurella multocida, and Histophilus somni isolated from the lower respiratory tract of healthy feedlot cattle and those diagnosed with bovine respiratory disease. Vet Microbiol. 2017;208:118-25.

30. EFSA. EMA and EFSA joint scientific opinion on measures to reduce the need to use antimicrobial agents in animal husbandry in the European Union, and the resulting impacts on food safety (RONAFA). EFSA Journal. 2017;15, 4666

31. Giguère S, Prescott JF, PM D. Antimicrobial Therapy in Veterinary Medicine Fifth ed. Ames Wiley Balckwell; 2013. p. 199-210.

32. Sarangi LN, Thomas P, Gupta SK, Priyadarshini A, Kumar S, Nagaleekar VK, et al. Virulence gene profiling and antibiotic resistance pattern of Indian isolates of Pasteurella multocida of small ruminant origin. Comp Immunol Microbiol Infect Dis. 2015;38:33-9.

33. Dayao DA, Gibson JS, Blackall PJ, Turni C. Antimicrobial resistance in bacteria associated with porcine respiratory disease in Australia. Vet Microbiol. 2014; 171(1-2):232-5.

34. Borge C, Cuevas I, Rodríguez-Guerra MA, Carbonero A, Perea A. Tildipirosin subcestibility of Pasteurella multocida Type A, Type B and Erysipelothrix rhusiopathiae associated with acute mortality in swine. Prague: 9th European symposium of porcine health management (ESPHM); 2017.

35. Townsend KM, Frost AJ, Lee CW, Papadimitriou JM, Dawkins HJ. Development of PCR assays for species- and type-specific identification of Pasteurella multocida isolates. J Clin Microbiol. 1998;36(4):1096-100.

36. Townsend KM, Boyce JD, Chung JY, Frost AJ, Adler B. Genetic organization of Pasteurella multocida cap loci and development of a multiplex capsular PCR typing system. J Clin Microbiol. 2001;39(3):924-9.

37. Fegan N, Blackall PJ, Pahoff JL. Phenotypic characterisation of Pasteurella multocida isolates from Australian poultry. Vet Microbiol. 1995;47(3-4):281-6.
38. Blackall PJ, Pahoff JL, Bowles R. Phenotypic characterisation of Pasteurella multocida isolates from Australian pigs. Vet Microbiol. 1997;57(4):355-60.

39. CLSI. Performance standards for antimicrobial disk and dilution susceptibility test for bacteria isolated from animals; aprroved standard-fourth edition- document VET01-A4. Wayne: Clinical and Laboratory Standards Institute; 2013.

40. WHO. Haemorrhagic Septicaemia. 2013. https://www.oie.int/fileadmin/ Home/eng/Animal_Health_in_the_World/docs/pdf/Disease_cards/ HAEMORRHAGIC_SEPTICEMIA.pdf.

41. CLSI. Performance standards for antimicrobial disk and dilution susceptibility test for bacteria isolated from animals. Document VET01-S. Wayne: Clinical and Laboratory Standards Institute; 2013.

42. Schwarz S, Silley P, Simjee S, Woodford N, van Duijkeren E, Johnson AP, et al. Editorial: assessing the antimicrobial susceptibility of bacteria obtained from animals. J Antimicrob Chemother. 2010;65(4):601-4.

\section{Publisher's Note}

Springer Nature remains neutral with regard to jurisdictional claims in published maps and institutional affiliations.
Ready to submit your research? Choose BMC and benefit from:

- fast, convenient online submission

- thorough peer review by experienced researchers in your field

- rapid publication on acceptance

- support for research data, including large and complex data types

- gold Open Access which fosters wider collaboration and increased citations

- maximum visibility for your research: over $100 \mathrm{M}$ website views per year

At $\mathrm{BMC}$, research is always in progress.

Learn more biomedcentral.com/submissions 